\title{
Rancang Bangun Alat Ukur Viskositas Dalam Rangka Pengembangan Modul Praktikum Fisika Dasar
}

\author{
Syafitri Jumianto $^{1 *}$, Anwar Mujadin ${ }^{2}$, Dewi Elfidasari ${ }^{3}$ \\ ${ }^{1,3}$ Program Studi Biologi, Fakultas Sains dan Teknologi, \\ Universitas Al Azhar Indonesia, Jl. Sisingamangaraja, Jakarta 12110 \\ ${ }^{2}$ Program Studi Teknik Elektro, Fakultas Sains dan Teknologi, \\ Universitas Al Azhar Indonesia, Jl. Sisingamangaraja, Jakarta 12110 \\ *Penulis untuk Korespondensi: syafitri@uai.ac.id
}

\begin{abstract}
Pengukuran viskositas metode bola jatuh menggunakan sensor proximity sebagai detektor pencatat waktu jalannya bola tersebut. Sensor diantarmukakan (interfacing) dengan mikrokontroler dihubungkan ke tampilan LCD dan dapat pula dihubungkan ke komputer melalui kabel USB yang kemudian diolah menggunakan program Labview. Komputer akan menampilkan hasil pencatatan waktu awal dan akhir perjalanan bola. Dengan memasukan data rumus, monitor komputer akan menampilkan nilai viskositas fluida yang di uji.
\end{abstract}

Abstract - Viscosity measurement falling ball method using proximity sensors as detectors running ball timers. Sensor interfaced with a microcontroller connected to the LCD display and can also be connected to a computer with USB cable and then processed using Labview program. The computer will display the result of recording of a ball trajectory from the start until finish. By inputing data formulas, computer monitors will display the value of the fluid viscosity.

Keywords - Viscosity, Sensor proximity, Labview.

\section{PENDAHULUAN}

Penelitian ini diusulkan sebagai penyempurnaan dan pengembangan cara pengukuran viskositas metode bola jatuh dengan meminimalisir kelemahan yang ada didalamnya, terutama dalam pencatatan waktu, sehingga diperoleh data viskositas yang akurat. Penyempurnaan alat yang dilakukan dalam penelitian ini adalah menggunakan sensor proximity sebagai detektor pencatat waktu jalannya bola tersebut. Sensor diantarmukakan (interfacing) dengan mikrokontroler dihubungkan ke komputer melalui kabel USB yang kemudian diolah menggunakan program Labview. Komputer akan menampilkan hasil pencatatan waktu awal dan akhir perjalanan bola.

Adapun diagram blok dari "Rancang Bangun Alat Ukur Viskositas Dalam Rangka Pengembangan Modul Praktikum Fisika Dasar" diperlihatkan pada Gambar 1.

Dengan memasukan data rumus, monitor komputer akan menampilkan nilai viskositas fluida yang di uji. Tujuan penelitian ini adalah:

1. Menyempurnakan sistem pencatat waktu pada pengukuran viskositas metode bola jatuh menggunakan sensor proximity.

2. Mengembangkan sistem pengukuran viskositas metode bola jatuh berbasis komputer.

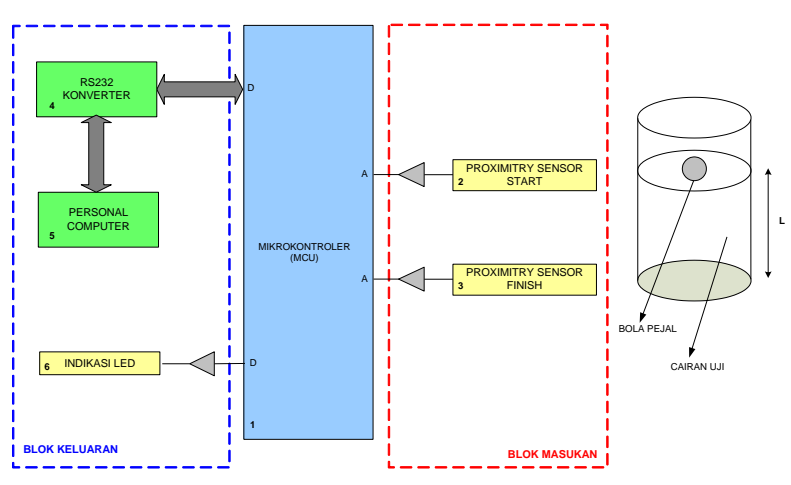

Gambar 1. Diagram Blok Alat ukur viskositas 
Diharapkan dari rancang bangun alat ukur viskositas ini akan mempunyai beberapa kelebihan yaitu pencatatan akan lebih cepat dan nilai yang dicatatnya valid, dan data-data tersebut dapat di record oleh komputer dan hal ini menjadi sarana untuk penelitian viskositas lebih lanjut.

Manfaat penelitian ini dengan dihasilkannya alat ukur viskositas menjadikan salah satu tahapan untuk mendukung pengembangan pengadaan alat yang lebih mutakhir dengan menggunakan komputer di Laboratorium Fisika Dasar. Selain itu juga untuk meningkatkan fungsi laboratorium sebagai tempat penunjang pelayanan pendidikan, penelitian, dan pengabdian masyarakat.

\section{TINJAUAN PUSTAKA}

Setiap benda yang bergerak relatif terhadap benda lain selalu mengalami gesekan (gaya gesek). Sebuah benda yang bergerak di dalam fluida juga mengalami gesekan.

Hal ini disebabkan oleh sifat kekentalan (viskositas) fluida tersebut. Koefisien kekentalan suatu fluida (cairan) dapat diperoleh dengan menggunakan percobaaan bola jatuh di dalam fluida tersebut yang diperlihatkan pada Gambar 2 berikut.

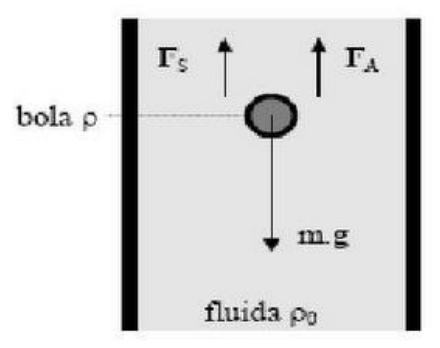

Gambar 2. Gaya-gaya bola dalam fluida

$$
\begin{aligned}
& \sum F=0 \\
& F_{A}+F_{f}-w=0 \\
& F_{A}+F_{f}=w \\
& F_{f}=w-F_{A} \\
& 6 \pi+\eta v=\rho_{b}-V_{b} \cdot g-\rho_{f} \cdot g \cdot V_{b} \\
& \eta=\frac{V_{b} \cdot g\left(\rho_{b}-\rho_{f}\right)}{6 \pi r v} \\
& \eta=\frac{4 / 3 \pi r^{3} \cdot g\left(\rho_{b}-\rho_{f}\right)}{6 \pi r v} \\
& \eta=\frac{2 / 9 r^{2} \cdot g\left(d_{\text {bola }}-d_{\text {fluida }}\right)}{v_{\text {rata-rata }}}
\end{aligned}
$$

Dimana:

$\eta=$ koefisien viskositas fluida;

$\mathrm{r}=$ jari jari bola;

$\mathrm{g}=$ gravitasi;

$\mathrm{d}_{\text {bola }}=$ densitas bola;

$\mathrm{d}_{\text {fluida }}=$ densitas fluida;

$\mathrm{v}_{\text {rata-rata }}=$ rata-rata kecepatan bola jatuh

Dalam penelitian ini menggunakan sensor untuk membantu pencatatan waktu jalannya peluru bola. Sensor yang digunakan yaitu sensor proximity. Sensor ini menerapkan prinsip Efek Hall yang diperlihatkan pada Gambar 3. Pada tahun 1879 Dr. Edwin Hall menetapkan efek yang dinamakan Efek Hall yang berasal dari namanya sendiri.

Dia menemukan sifat khusus dari tembaga dan kemudian semikonduktor yang lain yang dapat menghasilkan tegangan dalam medan magnet. Ini adalah merupakan sifat utama dari germanium dan indium. Efek Hall sebenarnya digunakan untuk wattmeter dan gaussmeter, dan sekarang juga digunakan untuk sensor proximity

Pertama-tama sumber tegangan eksternal digunakan untuk menghasilkan arus (I) pada semikonduktor kristal. Tegangan output $(V h)$ melewati bagian dari kristal secara tegak lurus dengan arah arus. Ketika medan magnet didekatkan

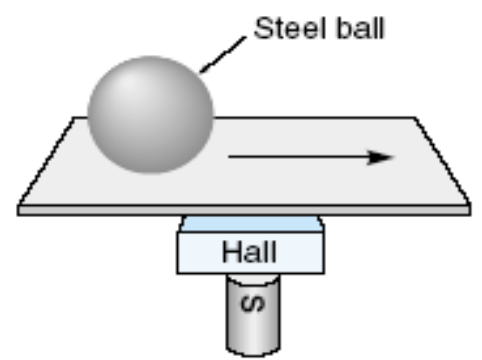

Gambar 3. Prinsip kerja sensor

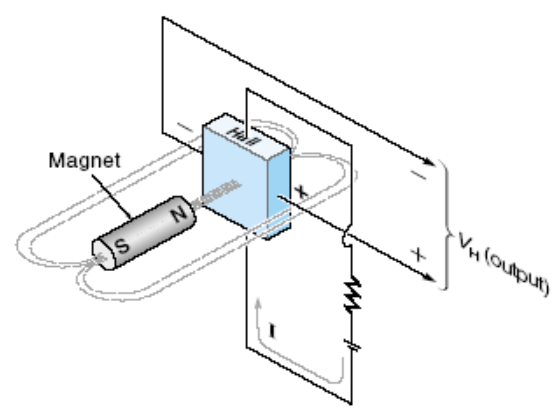

Gambar 4. Prinsip kerja efek Hall menghasilkan tegangan 
maka tegangan negatif akan dibelokkan ke satu sisi untuk menghasilkan tegangan yang diperlihatkan pada Gambar 4.

$\mathrm{V}_{\mathrm{H}}=\frac{\mathrm{KIB}}{D}$

Dimana :

$\mathrm{V}_{\mathrm{H}}=$ Tegangan Efek Hall

$\mathrm{K}=$ Konstanta (bergantung pada material)

$\mathrm{I}=$ Arus dari sumber eksternal

$\mathrm{B}=$ Medan magnet

$\mathrm{D}=$ Konstanta ketebalan

Selanjutnya dalam pengambilan dan pengolahan data menggunakan LabVIEW yang merupakan software yang khusus digunakan untuk pemrosesan dan visualisasi data dalam bidang akuisisi data, kendali dan instrumentasi, serta otomatisasi industri. Software ini pertama kali dikembangkan oleh perusahaan Nasional Instrumen (NI) pada tahun 1986. LabVIEW merupakan kepanjangan dari Laboratory Virtual Instrument Engineering Workbench.

Salah satu kelebihan LabVIEW dibandingkan dengan bahasa pemrograman lainnya adalah bahasa pemrograman LabVIEW jelas dan mudah dipahami, karena berbentuk grafis, dengan instruksi berbentuk ikon-ikon, yang dihubungkan dengan garis/kawat untuk menunjukan aliran data, mirip seperti flowchart

\section{METODE PENELITIAN}

Penelitian ini menggunakan metoda uji coba sehingga didapatkan hasil berupa piranti pengukuran serta software program yang dapat menampilkan hasil pengukuran dan semua hasil pengukuran oleh alat dapat bekerja sesuai dengan fungsinya baik perangkat keras maupun perangkat lunaknya. Komponen utama yang diperlukan dalam penelitian ini adalah: Sensor, Mikrokontroler, Power Suplay, LabVIEW software program (komputer). Tahapan pertama mendisain letak sensor proximity pada sisi tabung untuk mendeteksi waktu start awal bola pejal yang jatuh. Untuk pengkoneksian sensor komputer digunakan sebuah piranti MAX232 yang menyediakan port RS232.

Uji coba kelayakan dinyatakan berhasil apabila semua parameter dalam fitur prototipe dinyatakan lolos dan memenuhi spesifikasi. Salah satunya adalah instrumen untuk mengukur lamanya waktu tempuh bola pejal yang terdeteksi oleh sensor dapat bekerja dengan baik dan nilai viskositas yang fluida yang di uji bernilai sama dengan membandingkan nilai standar viskositas fluida uji tersebut.

Dalam pengujian alat ini juga mengikuti metoda pelaksanaan praktikum sesuai modul praktikum mengenai percobaan hukum Stokes (viskositas) dengan diawali persiapan bahan dan alat, langkahlangkah jalannya percobaan, pengamatan/ pengumpulan data, dan analisa.

\section{HASIL DAN PEMBAHASAN}

Uji coba kelayakan dinyatakan berhasil apabila semua parameter dalam fitur prototipe dinyatakan lolos dan memenuhi spesifikasi. Salah satunya adalah instrumen untuk mengukur lamanya waktu tempuh bola pejal yang terdeteksi oleh sensor proximiti dapat bekerja dengan baik dan nilai viskositas yang fluida yang di uji bernilai sama dengan membandingkan nilai standar viskositas fluida uji tersebut. Semua hasil pengukuran oleh alat diharapkan dapat bekerja sesuai dengan fungsinya baik perangkat keras maupun perangkat lunaknya.

Dalam modul praktikum mengenai Hukum Stokes (mengenai viskositas), alat dan perlengkapan yang harus disiapkan . Adapun tahapan percobaan yang harus dilakukan adalah sebagai berikut :

1. Mengukur diameter bola dengan mikrometer sekrup dan menimbang bola dengan neraca teknis.

2. Ukur diameter bagian dalam dari tabung dengan jangka sorong

3. Catat temperatur fluida sebelum dan sesudah percobaan

4. Ukur rapat massa fluida sebelum dan sesudah percobaan dengan aerometer

5. Tempatkan sensor 1 di luar tabung kira-kira 15 $\mathrm{cm}$ di bawah permukaan fluida dan sensor 2 dibagian bawah dengan jarak $15 \mathrm{~cm}$ (jarak jatuh 1) dari sensor 1

6. Masukkan sendok saringan sampai dasar tabung, tunggu sebentar hingga zat cair diam

7. Ukur waktu jatuh $\mathrm{T}$ untuk bola (T akan diukur oleh sensor 1 dan 2)

8. Ubah letak sensor hingga jarak d berubah (jarak sensor 2 diubah hingga berjarak $25 \mathrm{~cm}$ dan 35 $\mathrm{cm}$ dari sensor 1), lakukan langkah 6 hingga 7. 
Di dapat dari data awal pengamatan untuk uji fluida minyak goreng diperlihatkan pada Tabel 1 berikut.

Kemudian data tersebut diinput kedalam labview dan hasilnya diperlihatkan pada Gambar 5 berikut.

Tabel 1. Data pengamatan uji minyak goreng

\begin{tabular}{ll}
\hline \multicolumn{1}{c}{ Data Pengamatan } & \multicolumn{1}{c}{ Nilai } \\
\hline Massa bola $\left(\mathrm{M}_{\mathrm{b}}\right)$ & $0,05 \mathrm{~kg}$ \\
Diameter bola & $0,016 \mathrm{~m}$ \\
Massa jenis minyak & $800 \mathrm{~kg} / \mathrm{m}^{3}$ \\
goreng & \\
\hline
\end{tabular}

\begin{tabular}{|c|c|}
\hline \multicolumn{2}{|c|}{ Koefisien Viskositas Minyak Goreng } \\
\hline 60.4254 & $\mathrm{Ns} / \mathrm{m}^{3}$ \\
\hline Diameter Bola & Jari-jari Bola \\
\hline 6) $0.016 \quad m$ & $\sqrt{0.008} \mathrm{~m}$ \\
\hline Massa Bola & Massa Jenis Bola \\
\hline c) $0.05 \mathrm{~kg}$ & $\sqrt{23304.3} \mathrm{~kg} / \mathrm{m}^{3}$ \\
\hline Massa Jenis Fluida & Volume Bola \\
\hline f) $880 \mathrm{~kg} / \mathrm{m}^{3}$ & $2.145524 \mathrm{E}-6 \mathrm{~m}^{3}$ \\
\hline Gravitasi & Kecepatan Bola \\
\hline (3) $9.8 \mathrm{~m} / \mathrm{s}^{2}$ & $\longdiv { 0 . 0 5 1 7 2 4 1 } \mathrm { m } / \mathrm { s }$ \\
\hline \multirow{2}{*}{$\begin{array}{l}\text { Jarak Tempuh Bola } \\
\text { G) } 0.15 \mathrm{~m}\end{array}$} & Waktu Tempuh Bola \\
\hline & 6) 2.9 \\
\hline \multirow{2}{*}{$\begin{array}{l}\text { Diameter Bola } \\
\text { b) } 0.016 \quad \mathrm{~m}\end{array}$} & Jari-jari Bola \\
\hline & $\sqrt{0.008} \mathrm{~m}$ \\
\hline Massa Bola & Massa Jenis Bola \\
\hline 5) $0.05 \mathrm{~kg}$ & $\sqrt{23304.3} \mathrm{~kg} / \mathrm{m}^{3}$ \\
\hline Massa Jenis Fluida & Volume Bola \\
\hline 6) $880 \mathrm{~kg} / \mathrm{m}^{3}$ & $\sqrt{2.145524 \mathrm{E}-6} \mathrm{~m}^{3}$ \\
\hline Gravitasi & Kecepatan Bola \\
\hline (9) $9.8 \mathrm{~m} / \mathrm{s}^{2}$ & $0.0531915 \mathrm{~m} / \mathrm{s}$ \\
\hline \multirow{2}{*}{$\begin{array}{l}\text { Jarak Tempuh Bola } \\
\text { 9) } 0.25 \mathrm{~m}\end{array}$} & Waktu Tempuh Bola \\
\hline & 6) $4.7 \mathrm{~s}$ \\
\hline \multirow{2}{*}{$\begin{array}{l}\text { Massa Bola } \\
0.05 \mathrm{~kg}\end{array}$} & Massa Jenis Bola \\
\hline & $\sqrt{23304.3} \mathrm{~kg} / \mathrm{m}^{3}$ \\
\hline Massa Jenis Fluida & Volume Bola \\
\hline 6) $880 \mathrm{~kg} / \mathrm{m}^{3}$ & $\sqrt{2.145524 \mathrm{E}-6} \mathrm{~m}^{3}$ \\
\hline Gravitasi & Kecepatan Bola \\
\hline 6) $9.8 \mathrm{~m} / \mathrm{s}^{2}$ & $0.0522388 \mathrm{~m} / \mathrm{s}$ \\
\hline Jarak Tempuh Bola & Waktu Tempuh Bola \\
\hline c) $0.35 \mathrm{~m}$ & 9) $6.7 \mathrm{~s}$ \\
\hline
\end{tabular}

Gambar 5. Tampilan Labview menghitung Koefisien viskositas Minyak Goreng pada jarak tempuh bola yang berbeda
Terlihat bahwa dari fluida yang diuji dalam hal ini minyak goreng didapat nilai viskositas yang mendekati sama. Pengujian ini dengan merubah posisi sensor dengan jarak $15 \mathrm{~cm}, 25 \mathrm{~cm}$ dan 35 $\mathrm{cm}$. Pengujian minyak goreng tersebut mempunyai koefisien viskositas $59,671 \mathrm{Ns} / \mathrm{m}^{3}$.

\section{KESIMPULAN}

Telah dibuat Alat Ukur Viskositas dalam rangka pengembangan modul praktikum fisika dasar dengan baik sesuai dengan fungsi dari masingmasing komponen alatnya. Walaupun ada perubahan terkait sensor agar lebih bisa berfungsi baik. Proses pengambilan data, pengolahan dan hasil sesuai yang diharapkan. Perbedaan hasil perhitungan koefisien viskositas dengan perubahan jarak tempuh bola ada sedikit perbedaan namun relatif mendekati sama, dikarenakan terkait penempatan jarak sensor yang kurang tepat.

Disarankan dalam melakukan percobaan harus hatihati agar fluida dalam tabung tidak tumpah terlebih mengenai perangkat elektronik. Saat menjatuhkan bola usahakan pada posisi tengah tabung agar bola dapat terdeteksi oleh sensor dengan baik. Untuk memindahkan posisi sensor dalam menentukan jarak tempuh bola agar lebih akurasi lagi dalam pengukuran jarak. Perlu pengembangan agar lebih baik lagi dari aspek tampilan alat dan penyesuaian modul praktikum.

\section{DAFTAR PUSTAKA}

[1] Sapiie S, Nishino O. 2005 "Pengukuran dan AlatAlat Ukur Listrik”, PT. Pradnya Paramita, Jakarta.

[2] Wardhana L, 2006 "Belajar Sendiri Mikrokontroler AVR Seri ATMega8535”, Penerbit Andi, Yogyakarta.

[3] Panenbaum, Andrew S, 2000 "Computer Networks", Prentice Hall, New Jersey.

[4] http://www.alldatasheet.com, "RS-232 Datasheet", 2007

[5] http://www.arcelect.com, "RS-232 Data Interface", 2006 